\title{
An Experimental Investigation of the Integration of Smart Building Components with Building Information Model
} (BIM)

\author{
Kereshmeh Afsari ${ }^{\mathrm{a}}$, Laura Florez ${ }^{\mathrm{b}}$, Emily Maneke $^{\mathrm{c}}$, and Mahdi Afkhamiaghda ${ }^{\mathrm{a}}$ \\ ${ }^{a}$ School of Construction Management Technology, Purdue University, USA \\ ${ }^{b}$ Department of Architecture and Built Environment, Northumbria University, UK \\ ${ }^{c}$ Department of Computer Graphics Technology, Purdue University, USA \\ E-mail: kafsari@purdue.edu, laura.florez@,northumbria.ac.uk, emaneke@purdue.edu, mafkhami@purdue.edu
}

\begin{abstract}
Building Information Modeling (BIM) is a methodology to digitally represent all the physical and functional characteristics of a building. Importantly, in smart buildings smart components that are enabled with sensing and actuation need to be modeled accurately within the BIM model. This data representation needs to include multiple status of the smart component based on their performance to guide the design and construction process. However, currently there is not a clear methodology or guideline on how to embed smart components in the BIM model. Visualization techniques have been developed based on CAD technology to integrate smart components in the building model but these techniques have not been applied to BIM environment. To accurately model smart components, the component must be more than a single status representation and must contain complete and accurate dynamic data of the smart component. In this research, data properties, visualization techniques, and categorization of smart components is investigated. Then, through an experimental investigation, nine smart components across five building disciplines are modeled and embedded in a BIM model of a smart space. The model includes parameters that facilitate the data representation of the smart components. Data properties, data organization, and simulation of the smart component within the building model is explained. Challenges and future research is discussed.
\end{abstract}

Keywords -

Smart Components; BIM; Smart Buildings; Sensors; Actuators

\section{Introduction}

Smart buildings are buildings that consist of several types of interconnected smart technologies and smart components that enable the building to run based on the data collected by the smart components. This data can enable the increased sustainability, occupant experience, financial performance, operational efficiency, and prestige of smart buildings [1]. To enable the design of smart buildings, development of the 3D model of the building and planning for context-aware design of such smart environment is critical for designers [2].

On the other hand, Building Information Modeling (BIM) is a methodology that utilizes a set of software tools and processes for facilitating the creation and use of the digital representation of the physical and functional characteristics of a building. BIM models are intelligent data-rich sources of building data that can be used through the lifecycle of a building to analyze buildings and inform design, construction, and maintenance decisions [3]. In fact, smart technologies can be embedded in building spaces and components, using smart objects to enhance the performance of the building. However, there is a lack of studies on how BIM can accurately represent smart objects and the data within the design and construction of smart buildings. There is no clear guideline on how to model smart components, how to accurately embed the required data within the BIM model, and how to organize the data associated with the smart components within the BIM model. There is a need to develop BIM use cases to indicate how smart objects can be modeled and embedded within the BIM model [4].

Importantly, smart technologies and components need to be integrated with BIM to accurately model and analyze smart components within smart buildings [4]. BIM can help the design and construction process with the opportunity to integrate smart components from the design phase as well as the post-construction and operation of the building while providing a data repository for the users and for its for maintenance $[2,4]$. Therefore, this research investigates how BIM can be used in the development of smart buildings during the 
design process and how smart objects can be embedded with organized data in the BIM model to guide the process of design and construction of smart buildings. The objective of this study is to investigate how data properties of smart objects can be integrated in BIM models embedding sensing and actuation data. This paper will first study the ways smart component properties can be captured. Next, existing visualization techniques and simulation strategies for smart components is discussed. Then, the study investigates the different categories of smart components and within an experiment, the study develops BIM models of multiple building disciplines of a given space in a use case scenario to discuss how smart components with required data can be embedded in the BIM model.

\section{Smart Components Data Properties}

Smart environments operate through a sensing and actuating paradigm. A smart environment requires sensors to collect data and to communicate with smart components. The microprocessors analyze the data received from the sensors and command the actuators to respond accordingly. The actuator then uses the sensor data to complete their actions. Recently this paradigm has shifted from a wired sensing and actuating connection to an Internet of Things (IoT) approach. Internet of Things is a technology to create a network of interconnected objects that do not require human interference to perform tasks. These tasks can fall into the three main categories of sensing, analytics, and visualization [5]. There has been studies on how to embed smart objects in the BIM model of a smart building. Zhang et al. [4] embedded smart components in a Revit model to later work with a facility management tool they developed for energy management functions. They specifically integrated the smart components so that they can be exported to Industry Foundation Classes (IFC) to enable interoperability through open BIM standard. Their approach uses (1) Revit's IFC shared parameter specifying IFCSensorType to indicate the sensor type within an IFC entity (2) element property in the smart component family for the actuator, for the type of smart object, and for the mark tag of an individual smart object. Their work provides a data exchange interface for their developed facility software through mapping the smart object's family property parameters to IFC text, then, to their facility software interface and also, the smart device through using three main data as output, input and control [4]. Their study does not specify the structure of the object properties in the family level and it does not contain types of smart components other than smart objects for energy management systems. Also, their framework relies on the IFC within EXPRESS technology and P21 encoding (STEP-file) which parses the IFC files, it created a disconnected environment [6] with the source of data in the BIM model that relies on exporting and importing files. The work by Dave et al. [7] has developed a web based solution called Otaniemi3D that can integrate smart devices with the BIM data to provide information about energy usage, occupancy, and user comfort. They have exported the BIM model to a static IFC file essentially for the data regarding spaces in the building. They do not add the smart component and all the required properties of the smart component to the original BIM model (in Revit). Instead, they remodel the Revit file to add sensor data through IFC shared parameters using IfcSensorType to specify the type of sensor (e.g. TEMPRETURESENSOR). Then, they load the IFC file into IFCOpenShell to visualize the model then translate it to the final web formats to be transferred to Otaniemi3D environment running on a web browser. They also mentioned that during the data translation process, IfcSensorType and IfcSpaces data are either missing or incorrectly mapped which is not fully fixed and automated as they describe [7]. There is currently a lack in knowledge of how to model smart components integrating required data properties through the design and construction process and how to visualize smart components data in the BIM model, especially pertaining to data regarding sensors, actuators, microprocessors and components with more than one status.

\section{Visualization of Smart Components}

Crigliano [8] developed a QCAD extension as a systematic approach to appropriately allocate and install sensor nodes in an indoor environment. These sensor nodes are essential to smart environments to ensure that smart components receive data upon which to act. The 2D modeled environment allows the layout of sensor nodes to be adequately visualized.

$\mathrm{Su}$ and Huang [2] proposed a Visualization System of Context-aware Application Scenario Planning (VS-CaSP) and developed a visualization tool for non-technology users. VS-CaSP allows designers to quickly plan and construct 3D environments through rule-based and 3D visualization techniques. While the system is functional and claimed to be easy-to-use, it is based on CAD and its functionalities need to be extended to fulfill the needs of a BIM Model. Additionally, the rule expressions need to be evaluated to ensure the representation of more complex requirements in smart buildings. In this study some of the recommendations in the study by $\mathrm{Su}$ and Huang [2] is used and extended to BIM modeling and smart component parameters in the use case development.

\subsection{Simulation Techniques}

Agent-Based Modeling (ABM) is a simulation approach to model complex, interacting systems of 
agents. Components are modeled agent by agent or interaction by interaction. $\mathrm{ABM}$ is distinguishable by its emphasis on modeling the agent's heterogeneity and the emergence of self-organization. It has a bottom-up approach, thus the system's behavior emerges from how individual heterogeneous agents interact with each other and their environment based on defined rules. These features offer a way to model systems with agents, who can learn and adapt from other agents [9], to assess how their interactions affect the system.

Discrete Event Simulation (DES) is another simulation approach that mimics system behavior. DES tracks the system's state during a length of time using a collection of state variables. The system's state can only change instantaneously and these changes are referred to as events [10]. ABM and DES can be useful as they can reflect the dynamic nature of smart components and capture complicated behavior, dependencies and interrelationships $[11,12]$. Although a simulation approach can be an effective technique, this is only possible if the simulation tool is integrated with the BIM authoring tool.

\section{Categorization of Smart Components}

Smart objects function based on sensing and actuation and they consist of sensors, microprocessors and actuators in order to connect with the surrounded environment in the building so that they can react accordingly $[13,14]$. Sensors read the real-time status of the environment and pass the input as a signal through a network for processing [15]. Sensors and actuators each act as a node in a Wireless Sensor Network (WSN) which can have the ability to work with other systems and devices such as the occupancy feedback system. Table 1 shows the different criteria which can be used for the categorization of smart objects.

Sensors can be categorized based on various criteria, many researchers $[16,17]$ have classified sensors based on their type and parameter they read from the outside environment (e.g. vibration, humidity, pressure etc.). However, a lot of other factors such the environment needs and complexities, [17], the phase of the project lifecycle $[18,19]$, and area of usage in buildings $[16,18]$ affect the criteria for categorization of sensors. As sensors receive information from their surroundings, they send the data as an electronic signal to the actuators, and actuators take action accordingly [14]. This makes the interaction and sequence of data transfer between sensors and actuators critical in the way they respond to the changes in their surrounded environment. As Liu et al. [19] have demonstrated, the sequence and type of data transfer can lead to different networks and systems, in addition, the type of output data from each sensor defines how the smart object would respond to the environment.
Table 1 Criteria for categorization of smart components

\begin{tabular}{|c|c|}
\hline $\begin{array}{l}\text { Categorization } \\
\text { Criteria }\end{array}$ & Example Categories \\
\hline Sensor Type & $\begin{array}{c}\text { Thermal } \\
\text { Humidity } \\
\text { Acoustic } \\
\text { RFID } \\
\text { Motion } \\
\text { Light } \\
\text { Vibration } \\
\text { Pollution } \\
\text { Pressure } \\
\text { Flow Rate } \\
\text { Plug Load Devices } \\
\text { Fire } \\
\text { Smoke }\end{array}$ \\
\hline Speed Needs & $\begin{array}{c}\text { Static } \\
\text { Mobile } \\
\text { Embedded } \\
\end{array}$ \\
\hline Building Phase & $\begin{array}{c}\text { Construction Plan and Design } \\
\text { Construction Safety Management } \\
\text { Site Facility and Material Management } \\
\text { Site Environment } \\
\text { Construction Process Management } \\
\text { Structural Inspection } \\
\text { Re- Structure \& Expansion }\end{array}$ \\
\hline $\begin{array}{l}\text { Areas of Usage } \\
\text { in Building }\end{array}$ & $\begin{array}{c}\text { HVAC System } \\
\text { Information and transformation (e.g. } \\
\text { sensing floors, high rise elevators) } \\
\text { Safety and Security (e.g. biometric } \\
\text { authentication access) } \\
\text { Maintenance and Facility Management } \\
\text { Modeling Building Occupancy } \\
\text { IT Equipment } \\
\text { Openings (window, door) Status }\end{array}$ \\
\hline $\begin{array}{l}\text { Component } \\
\text { Type }\end{array}$ & $\begin{array}{c}\text { Blinds } \\
\text { Door } \\
\text { Windows } \\
\text { Electrical Devices } \\
\text { Lights } \\
\text { Fan } \\
\text { Heater } \\
\text { Boiler } \\
\text { Urinals } \\
\text { Water closet } \\
\text { Facade }\end{array}$ \\
\hline $\begin{array}{l}\text { Building } \\
\text { Discipline }\end{array}$ & $\begin{array}{l}\text { Architectural } \\
\text { Mechanical } \\
\text { Electrical } \\
\text { Structural }\end{array}$ \\
\hline $\begin{array}{l}\text { Connection \& } \\
\text { Data Exchange }\end{array}$ & $\begin{array}{l}\text { Periodic } \\
\text { Conditional } \\
\text { Timeout } \\
\text { Interrupt } \\
\end{array}$ \\
\hline Output Data & $\begin{array}{c}\text { Booleans } \\
\text { Binary (e.g. Yes/No, Occupy/ Empty) } \\
\text { Continuous Range of Values }\end{array}$ \\
\hline
\end{tabular}

A threshold is defined for smart objects which they 
respond accordingly to that predefined value. According to Weng and Agarwal [16], these conditions contains a broad range of variables such as binary statements, Booleans, as well as continuous range of values. This study specifically investigates the BIM modeling in the design and construction phase with regard to capturing these conditions within the data properties of the smart components.

\section{An Approach to Information Modeling of Smart Components}

This study focuses on integrating smart components within BIM models and it was undertaken in two phases as explained below.

\subsection{Study Phase}

This research informed decisions on how to represent smart components and the data that the smart components would need to contain through the study of the current status of the modeling of smart components, previous work on smart components and smart technology. Then, to categorize smart components and parameters, all investigated smart components as well as their parameters and modeling requirements were listed and then went through a selection process to determine which smart components would be modeled in the experiment The overarching study process is depicted in Figure 1.

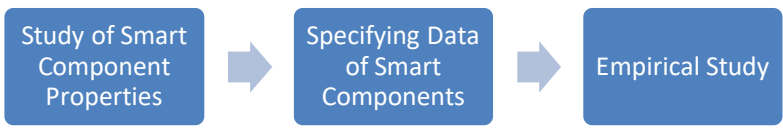

Figure 1. Overarching study process.

\subsection{Modeling Phase}

For the next step, to integrate smart components with the BIM model an experiment was designed for this empirical study and a use case was developed to represent the BIM model of the building in the experiment. A prototype was developed as the use case to integrate selected smart components. The model will be explained in more details in the following sections.

For the development of smart components and embedding them in the BIM model, the study first investigated several smart technologies as well as capabilities of the selected space within the use case. Then, nine smart components from five building disciplines were selected to be modeled and integrated in the BIM model. As mentioned in section 4, among categorization criteria for smart components, this study uses "Building Discipline" criteria to categorize and arrange the information regarding the smart components. Then, data properties were added to the developed smart components to represent the capabilities and data inputs and outputs received by the smart components. The data properties are provided for both sensing and actuating. Table 2 shows the list of selected smart components in this study and their object properties based on sensor parameters and actuator parameters.

Table 2. List of Modeled Smart Components and Their Object Parameters

\begin{tabular}{|c|c|c|c|}
\hline Category & $\begin{array}{l}\text { Smart } \\
\text { Object } \\
\text { Name } \\
\end{array}$ & $\begin{array}{c}\text { Sensor } \\
\text { Parameters }\end{array}$ & $\begin{array}{c}\text { Actuator } \\
\text { Parameters }\end{array}$ \\
\hline \multirow[t]{2}{*}{ Architectural } & Door & $\begin{array}{l}\text { Occupant's } \\
\text { Presence } \\
\text { Temperature }\end{array}$ & $\begin{array}{l}\text { Position } \\
\text { Angle }\end{array}$ \\
\hline & Window & $\begin{array}{l}\text { Humidity } \\
\text { Luminance } \\
\text { Occupancy } \\
\text { Temperature }\end{array}$ & $\begin{array}{l}\text { Opening } \\
\text { Distance }\end{array}$ \\
\hline \multirow[t]{2}{*}{ Electrical } & $\begin{array}{l}\text { Security } \\
\text { Alarm }\end{array}$ & $\begin{array}{c}\text { Surveillance } \\
\text { Status } \\
\text { Security Code } \\
\text { Occupancy } \\
\text { Windows } \\
\text { Doors } \\
\text { Lights }\end{array}$ & Alarm Status \\
\hline & Smart Plug & $\begin{array}{l}\text { Timer } \\
\text { Load }\end{array}$ & Status \\
\hline \multirow[t]{2}{*}{ Mechanical } & $\begin{array}{c}\text { Duct Static } \\
\text { Pressure } \\
\text { Sensor } \\
\end{array}$ & Resistance & Status \\
\hline & $\begin{array}{c}\text { Air } \\
\text { Handling } \\
\text { Unit }\end{array}$ & $\begin{array}{l}\text { Temperature } \\
\text { Humidity } \\
\text { Occupancy }\end{array}$ & Status \\
\hline Structural & $\begin{array}{l}\text { Structural } \\
\text { Deflection } \\
\text { Monitoring }\end{array}$ & Strain & $\begin{array}{c}\text { Compression } \\
\text { Force } \\
\text { Tension } \\
\text { Force } \\
\end{array}$ \\
\hline \multirow[t]{2}{*}{ Protection } & $\begin{array}{c}\text { Fire } \\
\text { Detection } \\
\text { Sensor }\end{array}$ & $\begin{array}{c}\text { Smoke } \\
\text { Detection } \\
\text { CO2 Detection } \\
\text { Temperature }\end{array}$ & $\begin{array}{c}\text { Resident } \\
\text { Notification } \\
\text { Fire } \\
\text { Department } \\
\text { Notification } \\
\text { Sprinkler } \\
\text { Activation }\end{array}$ \\
\hline & Sprinkler & $\begin{array}{l}\text { Sprinkler } \\
\text { Sensor }\end{array}$ & Status \\
\hline
\end{tabular}

For all of these smart components there are two additional properties as the "sensor type" and "actuator type" that is integrated as well. These smart components are used in the buildings with the means of providing occupant comfort, reducing energy consumption, and providing safety [1]. For example, fire protection is considered as one of the most important safety issues in 
the buildings as it can lead to damage and fatality, therefore it is of vital importance to have an immediate notification system for the occupants. Many researchers $[20,21]$ have used sensors capable of detecting any high rising amount of smoke, heat, or $\mathrm{CO} 2$ gas in the environment. Once the sensor detects any abnormal presence of these parameters in the environment, the input from sensors then goes to the actuator. Depending on the system design, the actuator parameter can be simple alarm system for notifying the occupants and the fire department all the way to activating sprinklers for preventing the fire from spreading [21]. Smart plug is another object integrated in this study. Shutting down any unnecessary or unused electronic is considered as one of the methods to reduce the electricity consumption of the building. In light of this subject, Weng and Agarwal [16] have suggested tracking the plug load of electronic devices, using this method, systems such as lighting and IT equipment which are not being used by occupants can be easily spotted and be turned off. For places such as offices or schools, where the occupant's system usage is predictable and follows a certain schedule, one can use timer sensors to turn off equipment in a specific time [22]. For the structural discipline in this study, a Structural Deflection Monitoring (SDM) system in embedded for monitoring dynamic deflection of columns and beams. In this system, the Long-gauge fiber Bragg grating (LGFBG) sensors can measure average strain over a certain length [23] and accordingly when needed, the actuator will apply compression or tension force measured in kips.

The next step is digital development of building using BIM authoring tools. In this study we use Autodesk Revit A medical waiting room was developed as the use case. In this research, the use case was selected within a commercial building. This part of the study allows a space to be developed with the integration of smart components into the building performance. By limiting the use case to one space within the building, the focus is on the smart components and their parameters as opposed to general building performance. This also allows for the ability to generalize the study findings upon completion of this one scenario. In fact, the prototype used for this study is a one story steel structure, 1300 square foot commercial waiting room facility with a front desk space. Each building disciple was housed in a separate model before being linked together using Revit linked features. Modeled building disciplines included architectural, structural, mechanical, electrical, and fire protection.

Next, is embedding smart components in the building. The BIM model was created considering the following sub-models: architectural, structural, mechanical, electrical, and fire protection. Each smart component categorized in Table 2 was embedded in the building model of its corresponding discipline as shown in Figure 2. Figure 3, 4 and 5 illustrate the BIM model data set developed as the prototype in this study.

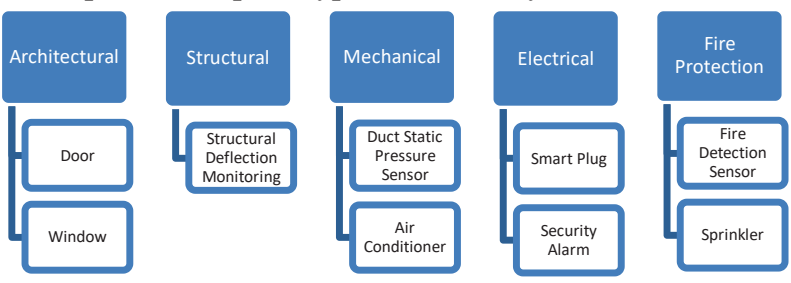

Figure 2. Building disciplines and smart components in the prototype
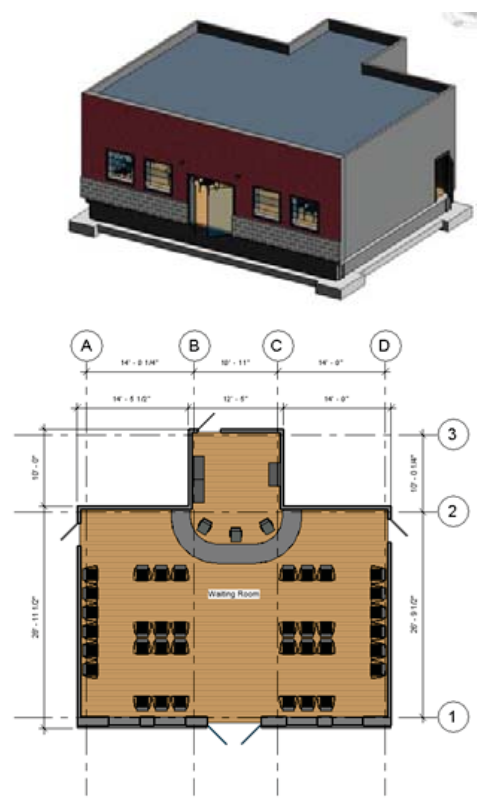

Figure 3. Top: Merged BIM Model; Bottom: First Floor Architectural Plan
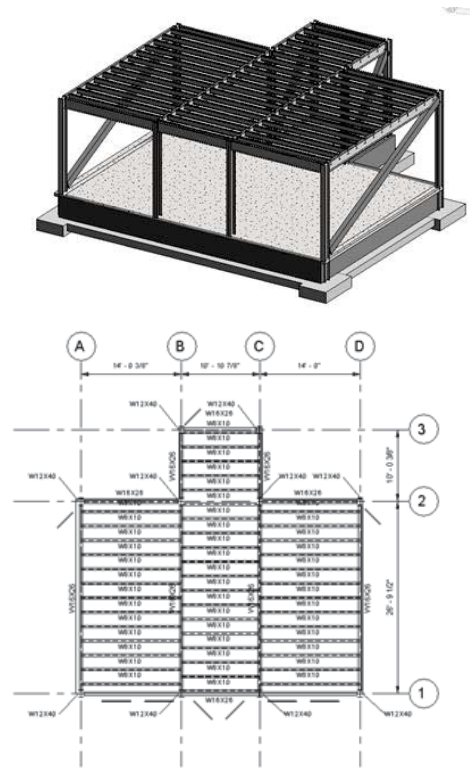

Figure 4. Top: Structural BIM Model; Bottom: First Floor Framing Plan 


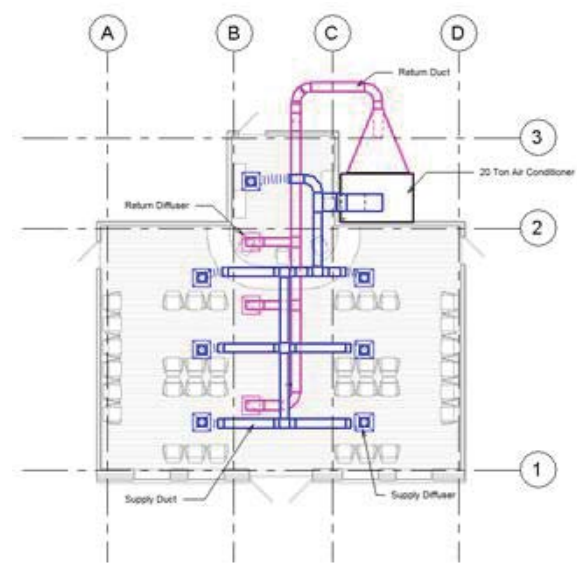

Figure 5. Mechanical Ductwork Floor Plan

\section{$6 \quad$ Results}

One of the challenges regarding the integration of smart components with the BIM model of the smart building is the static nature of current BIM authoring tool which limits the data representation of smart components with multiple status in a dynamic environment. In this study, nine smart components across the five different building disciplines were modeled. Component parameters were developed based on the literature study in the initial study phase. In order to represent the parametric behavior of the smart components and most importantly to capture multiple status of the smart components to inform the design and construction process, experimental equations were used to represent the interrelations of the sensor and actuator. Experimental equations for the parameters of the nine smart component are shown in Table 3.

For each smart component a parametric object is modeled and all the parameters and equations are embedded in the model. For instance, for the automatic door a parametric one panel door was modeled. Standard attributes such as height, width, and thickness were used to model the door. Other parameters involving the integrated smart technology including sensor type, actuator type, and opening angle were assigned to the door. To enable the data representation of the automatic door capabilities, parameters were added for presence and temperature. The presence parameter was assigned an integer of 0 or 1 , where 0 designates no presence detected and 1 designates presence detected. Similarly, the temperature parameter was assigned an integer of 0 or 1 , where 0 designates the temperature is within the specified range and 1 designates the temperature is outside of the specified range. An experimental equation was developed such that the opening angle of the door was controlled by the presence and temperature parameters, Angle $=$ (Presence x 45 degrees) + (Temperature x 45 degrees). Based on inter-related sensor-actuator rules [2] this methodology has enabled the data representation of automatic door data in the BIM model to inform the design and construction process with multiple status of the smart object.

Table 3. Simulation Equations for smart components

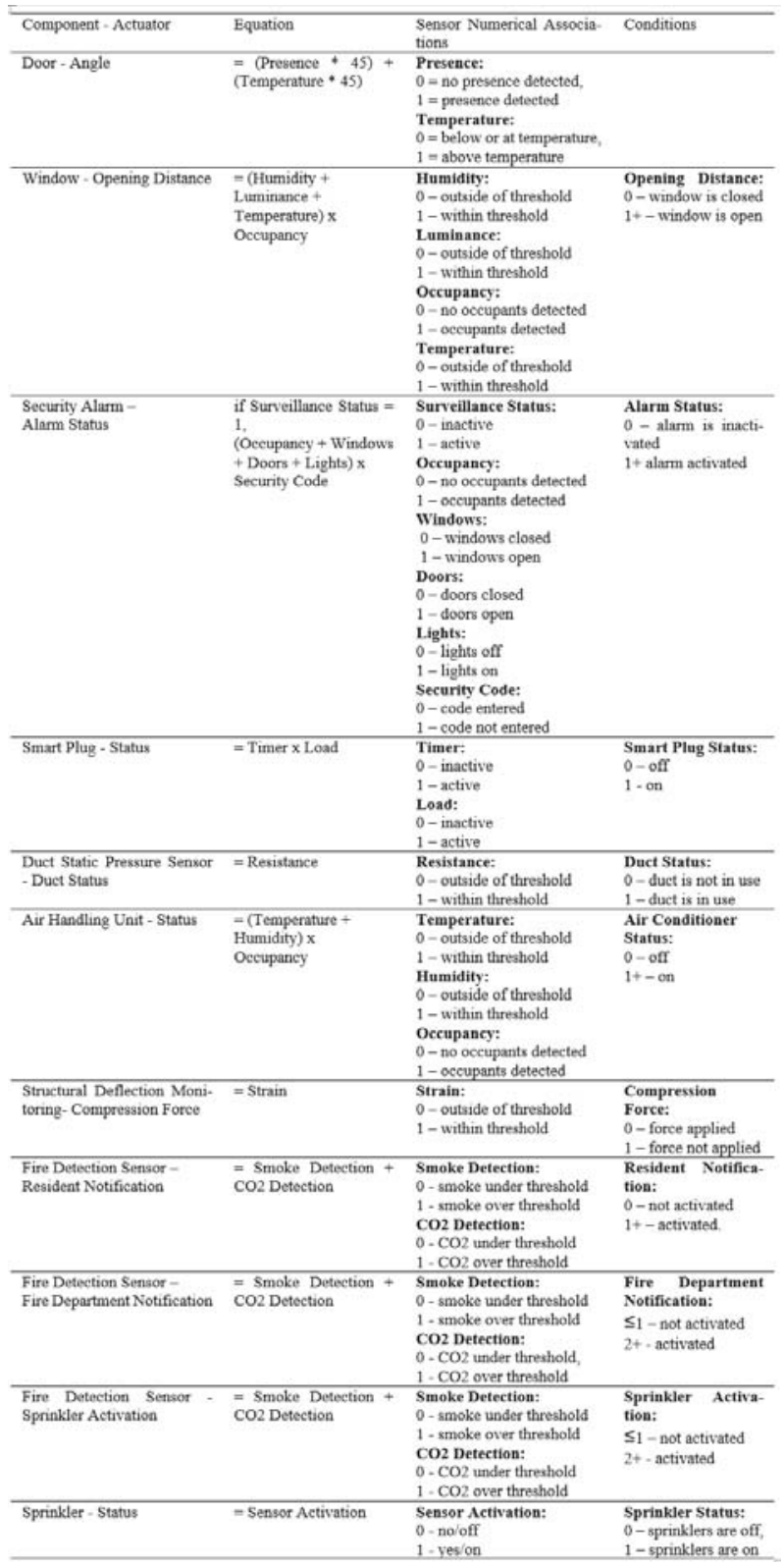

Also, an air handling unit was modeled in the way that its parameters such as temperature, humidity, and occupancy were added to the component. The temperature parameter was assigned an integer of 0 or 1 , where 0 designates the temperature is within the specified range and 1 designates the temperature is outside of the specified range. The humidity parameter was assigned an integer of 0 or 1 , where 0 designates the humidity is 
within the specified range and 1 designates the humidity is outside of the specified range. The occupancy parameter was assigned an integer of 0 or 1 , where 0 designates no occupancy detected and 1 designates occupancy detected. An experimental equation was developed such that the on/off status of the air handling unit was controlled by the temperature, humidity, and occupancy parameters while Status $=$ (Temperature + Humidity) x Occupancy thus can inform the design and construction process. Figure 6 shows the family parameters modeled in Revit for the smart air handling unit developed in this study.

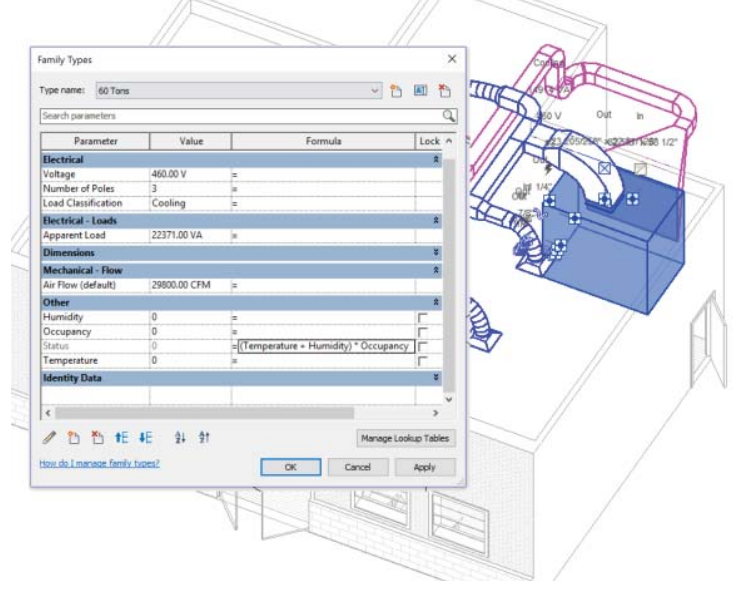

Figure 6. Family Parameters for the Smart Air Handling Unit

Once the parameters and equations have been established for each of the components in the model (see Table 3), these can be integrated into a simulation model. The simulation model takes two types of input information. The first type of input is the components' parameters obtained from the smart components data properties. The second type of input is the value range of a parameter, which depicts the status from the low-start point of the first event to the last-finish point of the last event in the process. To represent the behavior of the system, the simulation model considers the components (with its parameters) as agents and model these to capture their interactions and dependencies. The model may also adjust probability distributions to the parameters of the smart components, which defines the status of the component. By modelling agents, the simulation phase aims to predict the smart components' values that will serve as inputs for the actuator. The input to the simulation phase includes the probability distributions of the components' values (with the maximal status for each parameter), which allow generating multiple scenarios using random numbers drawn from the probability distributions. Additionally, the model can also estimate the parameters by fitting probability distributions. Fitting methods allow selecting the parameters that produce the best fit to the collected data. With this fitted distributions, it is possible to replicate the components' values.

The results from the simulation model can then be integrated to the BIM authoring tool to digitally represent the smart components and better manage information to guide the process of design and construction of smart buildings. With the information collated from the simulation model into the BIM tool, it is expected that a rich data file can be produced for optimizing the facilities management process. The reader is referred to [24] for a detailed description on how to integrate information and create COBie (Construction Operations Building Information Exchange) data for the facilities management process. COBie data comes directly from the building information. This information is collected, stored and linked (using COBie) and COBie deliverables become the monitor and decision support documents to be updated and managed.

\section{Discussion and Conclusion}

This study investigated the data properties of smart components with the purpose to be embedded in the BIM model while capturing smart components conditions with required sensing and actuation to inform the design and construction process. Future research will study data flow and interaction of smart components in the BIM model and smart devices. In this study, several smart components were modeled with their corresponding parameters to enable their accurate representation and data capabilities. While these smart components can hold relevant data, this data must be embedded manually for each component individually as parameters are not identical among the components. Future research should evaluate the effectiveness of the smart component data representations created in this study.

Other modeling challenges pertained to visualization. While the opening angle of a door can easily be seen as the inputted data changes, actuations such as air handling unit status are harder, if not impossible, to visualize. Instead, one must look at the data parameters to determine the component's status in a dynamic smart environment. Similarly, developing equations that simulated the components' actuations proved challenging. As several sources of sensor data affect the component's actuations, the interrelations of the data needs to be captured while creating the data representation. Future research should evaluate simulation equations to more accurately represent the interconnected inputs and behaviors of the various smart components. To accomplish this, future work may look toward integrating computational solutions and if/then rule principles into the BIM smart framework. BIM software systems such as Revit are currently a static methodology that does not lend itself to depicting smart components that constantly read, evaluate, and respond 
to their environment. Hence, the manual input of device data is necessary in current BIM solutions. As such, future solutions should turn toward BIM enabled with simulation strategies to integrate smart components representation with the building model.

\section{References}

[1] Brown, S., Karnatz, K., \& Knight, R. A comprehensive look at the intelligent building. Consulting Specifying Engineer, 53(3): 54-58. 2016.

[2] Su, J., \& Huang, C. An easy-to-use 3D visualization system for planning context-aware applications in smart buildings. Computer Standards \& Interfaces, 36(2): 312-326. 2014.

[3] Teicholz, P. BIM for Facility Managers. John Wiley \& Sons: Hoboken, NJ, USA. 2013.

[4] Zhang, J. C., Seet, B. T., \& Lie, T. Building Information Modelling for smart built environments. Buildings, 5(1): 100-115. 2015.

[5] Gubbi, J., Buyya, R., Marusic, S., \& Palaniswami, M. Internet of Things (IoT): A vision, architectural elements, and future directions. Future Generation Computer Systems, 29(7): 1645-1660. 2013.

[6] Afsari, K. Standard-based Data Interoperability of the Building Information Model in Cloud. In Proceedings of the $54^{\text {th }}$ ASC Annual International Conference, April 18-21, Minneapolis, MN. 2018.

[7] Dave, B., Buda, A., Nurminen, A., \& Främling, K. A framework for integrating BIM and IoT through open standards. Automation in Construction, 95: 35-45. 2018.

[8] Cirigliano, A. Toward Smart Building Design Automation: Extensible CAD Framework for Indoor Localization Systems Deployment. IEEE Transactions on Computer-Aided Design of Integrated Circuits \& Systems, 37(1): 133-146. 2018.

[9] Macal, C. M., \& North, M. J. Tutorial on agentbased modelling and simulation. Journal of Simulation, 4(3): 151-162. 2010.

[10] Jacob, M. Discrete event simulation. Resonance, 18(1): 78-86. 2013.

[11] Siebers, P. O., MacAl, C. M., Garnett, J., Buxton, D. \& Pidd, M. (2010). Discrete-event simulation is dead, long live agent-based simulation. Journal of Simulation, 4(3), pp. 204-210.

[12] Sargent, R. G. (2015). An introductory tutorial on verification and validation of simulation models, In Yilmaz, L. et al. (eds) Proceedings of the 2015 Winter Simulation Conference. Huntington Beach, CA, USA: IEEE, pp. 1729-1740

[13] Kortuem, G., Kawsar F., Sundramoorthy V., and Fitton D. Smart objects as building blocks for the internet of things. IEEE Internet Computing 14(1):
44-51. 2010

[14] De Farias C., Soares H., Pirmez L., Delicato F., Santos I., Carmo L., Souza J., Zomaya A., and Dohler M. A control and decision system for smart buildings using wireless sensor and actuator networks. Transactions on Emerging Telecommunications Technologies, 25(1):120-135, 2014.

[15] De Guglielmo, D., \& Anastasi, G. Wireless sensor and actuator networks for energy efficiency in buildings. In Second IFIP Conference on Sustainable Internet and ICT for Sustainability (SustainIT 2012). IEEE. 2012.

[16] Weng, T. and Agarwal Y. From buildings to smart buildings - sensing and actuation to improve energy efficiency. IEEE Design \& Test of Computers. 29 (4): 36-44. 2012.

[17] Essa, I. A. Ubiquitous sensing for smart and aware environments. IEEE personal communications 7(5): 47-49. 2000.

[18] Arampatzis, T., Lygeros, J., \& Manesis, S. A survey of applications of wireless sensors and wireless sensor networks. In Intelligent Control, Proceedings of the 2005 IEEE International Symposium on Mediterrean Conference on Control and Automation: 719-724. IEEE. 2005.

[19] Liu Z., and Deng Z. A Systematic Method of Integrating BIM and Sensor Technology for Sustainable Construction Design. In Journal of Physics: Conference Series, 910(1). IOP Publishing, 2017.

[20] Silva B., Fisher R.M., Kumar A., Hancke, G.P. Experimental link quality characterization of wireless sensor networks for underground monitoring. IEEE Trans. Ind. Inform. 11:10991110. 2015.

[21] Saeed, F.; Paul, A.; Rehman, A.; Hong, W.H.; Seo, H. IoT-Based Intelligent Modeling of Smart Home Environment for Fire Prevention and Safety. J. Sens. Actuator Netw. 7(11). 2018.

[22] Gandhi, P., \& Brager, G. S. Commercial office plug load energy consumption trends and the role of occupant behavior. Energy and Buildings, 125: 1-8. 2016.

[23] Hong W, Qin Z, Lv K, Fang X. An Indirect Method for Monitoring Dynamic Deflection of Beam-Like Structures Based on Strain Responses. Applied Sciences. 8(5):811. 2018.

[24] Florez, L., \& Afsari, K. Integrating facility management information into building information modelling using COBie. In 35th International Symposium on Automation and Robotics in Construction and International AEC/FM Hackathon: The Future of Building Things (pp. 832-839). 2018. 